\title{
Determination of Setback Distances for On-Land Seismic Reflection Survey in Thailand
}

\author{
Tirawat Boonyatee $^{\mathrm{a}, *}$ and Nattawut Hemathulin ${ }^{\mathrm{b}}$ \\ Department of Civil Engineering, Faculty of Engineering, Chulalongkorn University, Bangkok, Thailand \\ E-mail: atirawat.b@chula.ac.th (Corresponding author), bh.nattawut28@gmail.com
}

\begin{abstract}
Explosives are commonly used to generate strong impulsive waves for on-land petroleum exploration. For each exploration area in Thailand, a concessionaire shall submit an environmental impact assessment report that commits minimum distances, or setback distances, between an explosive and various types of structures to a regulatory authority. However, the basis for determining the setback distances is not described and or based on surface mine blasting researches.

To establish a guideline for exploration contractors in Thailand, ground vibrations were measured from ten exploration sites across the country which can be grouped into three geology conditions, namely sandy ground, clayey ground and sandy ground with rock boulders. Explosives in this study were buried and packed in boreholes at depths of $9 \sim 23$ $\mathrm{m}$, having weights of $1 \sim 4 \mathrm{~kg}$ and length-to-diameter ratios of $6 \sim 25$.

The measured data were used for determining the attenuation of particle velocities over distance and the frequency content of vibrations. The geometric damping was found to be the main cause of attenuation while the material damping was negligible. The attenuation in sandy ground with rock boulders was found to be stronger than sandy ground and clayey ground. Since the dominant frequencies of vibration in each ground type varied over wide range, the frequencies at the 2.5th percentile were used for the conservative sake in the vibration assessment according to DIN 4150. Based the proposed formula, the setback distances between residential buildings and a 2-kg explosive are 53, 149 and $221 \mathrm{~m}$ for sandy with rock boulders, sandy and clayey grounds, respectively.
\end{abstract}

Keywords: Petroleum exploration, seismic reflection survey, setback distance, Thailand.

ENGINEERING JOURNAL Volume 21 Issue 3

Received 9 September 2016

Accepted 24 November 2016

Published 15 June 2017

Online at http://www.engj.org/

DOI:10.4186/ej.2017.21.3.51 


\section{Introduction}

Explosives are one of the most convenient sources for Seismic Reflection Surveys (SRS). When explosives are used, setback distances to existing structures are usually required for limiting damage caused by vibration. For each exploration area in Thailand, a concessionaire shall submit an environmental impact assessment report that commits minimum distances, or setback distances, between an explosive and various types of structures to the Department of Mineral Fuels (DMF). The current practice in Thailand is to provide setback distances of about 100-200 $\mathrm{m}$ for residential buildings and 500-2,000 $\mathrm{m}$ for historic buildings. These distances accompany typical charge weights of 1.0, 1.5, and $2.0 \mathrm{~kg}$ for sand, clay, and sandy with rock boulders grounds, respectively. Since the basis for determining the setback distances were not explained or based on measurements not directly related to SRS [1,2] it is not uncommon for a local authority to request for wider separation distances than the ones submitted to the DMF. This study is an attempt to reevaluate setback distances based on field measurements from petroleum exploration fields in Thailand.

The effects of blasting vibration are commonly justified by two parameters which are the Peak Particle Velocity (PPV) and the dominant frequency of vibration on the building of concern. These parameters depend, in turn, on the characteristics of vibration source, the ground and the building.

Vibration in surface mining occurs when rock or consolidated material is broken off from a vertical face by array blasting. In an array, explosives of weight $64 \sim 643 \mathrm{~kg}$ are detonated in sequence with a milliseconds delay time for the interest of reducing the magnitude of vibration [3-6]. The magnitude of vibration also depends on the explosive weight, the distance from explosives to adjoined free surface, the velocity of detonation and the acoustic impedance of the ground [7-11, 18]. A general form of equations for evaluation of blasting vibrations can be written as follows:

where: $v=$ peak particle velocity $(\mathrm{mm} / \mathrm{s})$

$$
v=k \cdot w^{b} \cdot r^{-n} \cdot e^{-\alpha r}
$$

$k, b, n, \alpha=$ non-negative fitting parameters (consistent unit, unit less, unit less, $\mathrm{m}^{-1}$ )

$w \quad=$ weight of explosive per delay $(\mathrm{kg})$

$r \quad=$ distance between the vibration source and evaluating point $(\mathrm{m})$.

The fitting parameters $b, n, \alpha$ in Eq. (1) were either empirically determined or theoretically assumed based on the geometry of explosive, geometric attenuation and material attenuation, respectively. The value of $n$ depends on source geometry, vibration type and wave type as shown in Fig. 1. The material attenuation is affected by various factors such as frequency and amplitude of vibration, soil type and increases with the degree of saturation [12,13]. The value of $\alpha$ falls in a range of $0 \sim 0.44 \mathrm{~m}^{-1}[14,15]$.

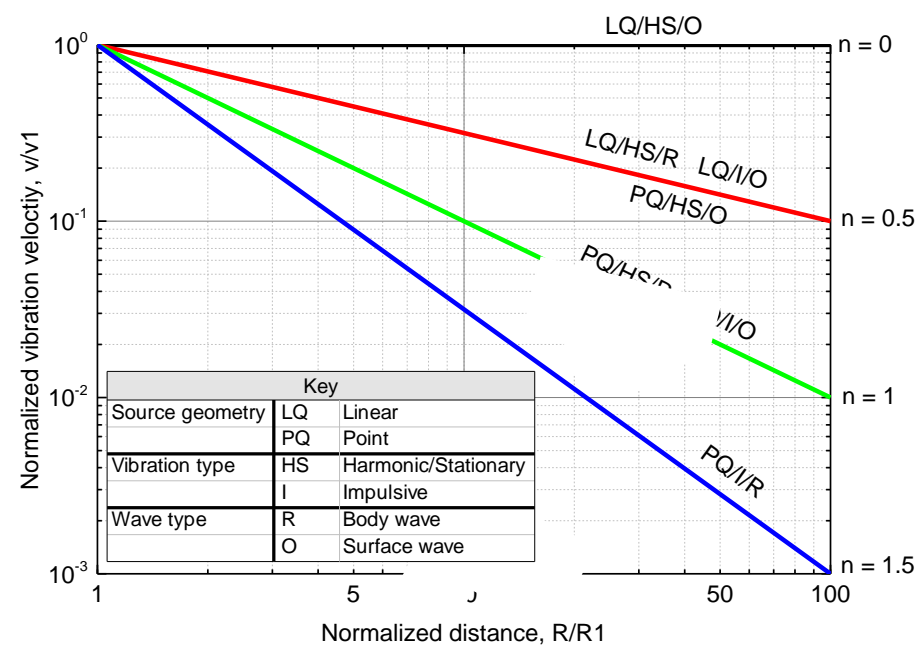

Fig. 1. Dependency of $n$ on source geometry, vibration type and wave type (after DIN 4150).

When the influence from explosive weight is not considered, the first two components in Eq. (1) can be lumped together for obtaining a simplified form as shown by Eq. (2). By assuming that the effect of the material attenuation is negligible, a more simplified model as shown by Eq. (3) can be obtained. 


$$
\begin{gathered}
v=\hat{k} \cdot r^{-n} \cdot e^{-\alpha r} \\
v=\hat{k} \cdot r^{-n}
\end{gathered}
$$

By introducing a notation of scaled distance and not (explicitly) considering the effect from material damping, Eq. (1) can be written as

$$
\begin{gathered}
v=k \cdot\left(\frac{r}{w^{\hat{b}}}\right)^{-n} \cdot e^{-\alpha r} \quad ; \hat{b}=b / n, \alpha=0 \\
v=k \cdot D^{-n}
\end{gathered}
$$

where $D$ is the scaled distance. The parameter $\hat{b}$ seems to be related to the geometry of explosive [16]. Some values of $\hat{b}$ reported in literatures are $1 / 3$ [17], 0.5 [19, 20], 2/3 [21, 22], and 1.5 [23].

\section{Blasting and Measuring Conditions}

By accompanying seismic reflection surveys at locations shown in Table 1, vibrations from their operations were recorded by calibrated geophones, consisting of four 2- $\mathrm{Hz}$ triaxial geophones and sixteen $4.5 \mathrm{~Hz}$ vertical geophones. In each study area, the geophones were installed on the ground surface at a regular interval and used to record vibrations from detonation points in nearby areas which correspond to separation ranges between $10 \sim 2,000 \mathrm{~m}$. The locations of instrument geophones and explosives were recorded by surveyor-grade GPS. Based on the geometric relationship, measured signals were transformed into radial, transverse and vertical directions as well as source-to-receiver distance.

All explosives in this study were emulsion explosives (Emulex) having the detonation velocity of 5,000 $-5,500 \mathrm{~m} / \mathrm{s}$. The weight of explosive in each study area was justified by exploration contractors. On the contrary to surface mine blasting, each seismic event in this study was generated from a single borehole

\begin{tabular}{|c|c|c|c|c|c|}
\hline \multicolumn{3}{|c|}{ Study areas } & \multicolumn{2}{|c|}{ Explosive } & \multirow[b]{2}{*}{ Ground condition } \\
\hline Site & District & Province & Weight $(\mathrm{kg})$ & $\begin{array}{l}\text { Buried depth } \\
\text { (m) }\end{array}$ & \\
\hline 1 & U Thong & Suphan Buri & 1.0 & $19-21$ & Saturate, Clayey \\
\hline 2 & Nong Wua So & \multirow[t]{2}{*}{ Udon Thani } & 1.5 & $5-9$ & $\begin{array}{c}\text { Dry, Sandy with rock } \\
\text { boulders }\end{array}$ \\
\hline 3 & Nong Wua So & & 2.0 & 9.6 & Dry Sandy \\
\hline 4 & Tha Khantho & Kalasin & 1.5 & 9.0 & $\begin{array}{c}\text { Dry, Sandy with rock } \\
\text { boulders }\end{array}$ \\
\hline 5 & Khemmarat & $\begin{array}{l}\text { Ubon } \\
\text { Rachatani }\end{array}$ & 1.5 & $5-12$ & $\begin{array}{c}\text { Dry, Sandy with rock } \\
\text { boulders }\end{array}$ \\
\hline 6 & Ampher Muang & Surat Thani & 2.0 & $15-19$ & Saturate, Sandy \\
\hline 7 & Yang Sisurat & \multirow{2}{*}{$\begin{array}{l}\text { Maha } \\
\text { Sarakham }\end{array}$} & 3.0 & 13 & Dry, Sandy \\
\hline 8 & $\begin{array}{l}\text { Phayakkhaphum } \\
\text { Phisai }\end{array}$ & & 3.0 & 13 & Dry, Sandy \\
\hline 9 & Phutthaisong & Buri Ram & 3.0 & 13 & Dry, Sandy \\
\hline 10 & Satuek & Surin & 4.0 & 13 & Dry, Sandy \\
\hline
\end{tabular}
which was prepared under flat unconsolidated ground. This configuration can be considered as single holeinfinity burden type.

Table 1. Summaries of ground conditions and explosive properties.

The sites were grouped from top 10 15 m layers into sandy ground, clayey ground, and sandy ground with rock boulders. Since the measurements at site 1 and 6 were carried out in a rainy season, groundwater level in these sites was close to the ground surface. Water bursts of $3 \sim 4 \mathrm{~m}$ high always occurred at detonation points in these areas. Photo of each ground type is shown in Fig. 2. 


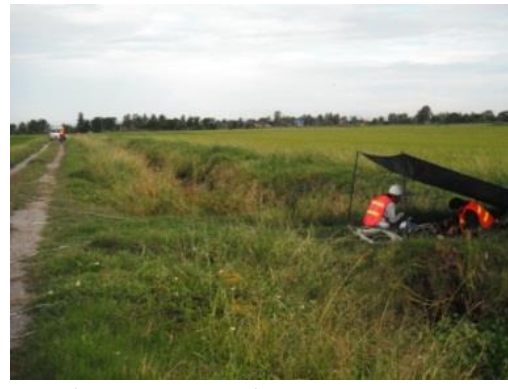

a) Clayey ground

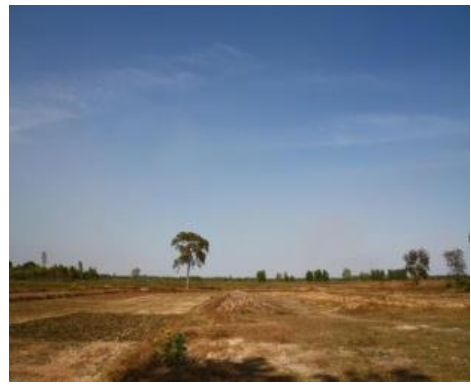

b) Sandy ground

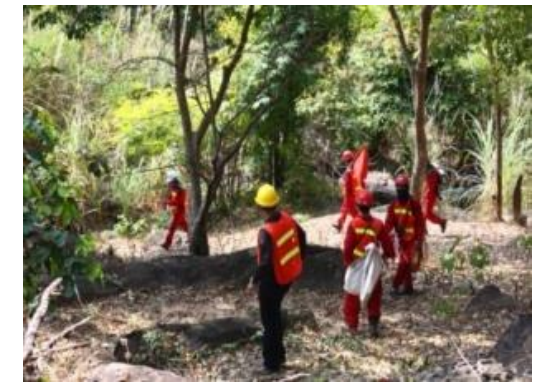

c) Sandy with rock boulders ground

Fig. 2. Photos taken from clayey, sandy and sandy with rock boulders ground sites.

\section{Results and Discussions}

\section{Vibration in Each Direction}

The maximum values were picked up from the recorded signals and plotted against the separation distance in Fig. 3. In this study, the maximum values of vibrations in each direction as well as the maximum value of the vibration vector were considered. The amplitude of a vibration vector at time $t\left(v_{s, t}\right)$ can be calculated by

$$
v_{s, t}=\sqrt{v_{r, t}^{2}+v_{t, t}^{2}+v_{z, t}^{2}}
$$

where $v_{r, t}, v_{t, t}, v_{z, t}$ are particle velocities in radial, transverse, and vertical directions at time $t$, respectively.

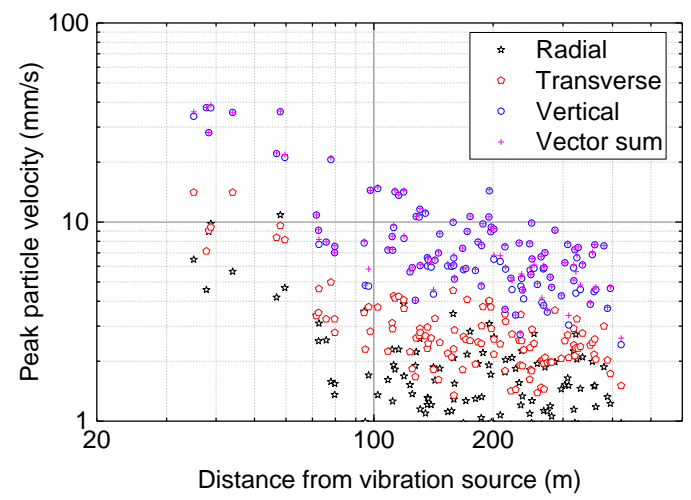

a) Clayey ground

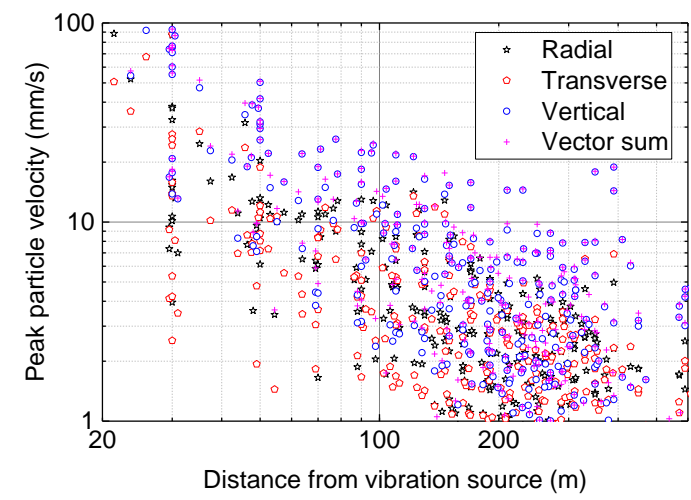

b) Sandy ground

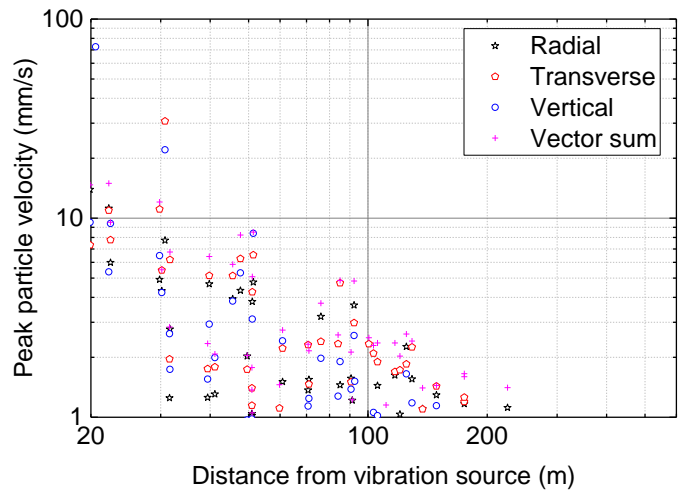

c) Sandy with rock boulders ground

Fig. 3. Vibration in each direction.

For clayey and sandy grounds, it can be seen that the values of vertical component were almost equal to the values from true velocity vectors and higher than the other two components. Therefore, it can be concluded that the vibrations were dominated by the vertical component. Based on this evidence, further 
analyses for these ground types were based on the data from $4.5 \mathrm{~Hz}$ vertical geophones for the interest of more data points.

On the contrary, the relationship between the true velocity vectors with the vibrations in each component was scattered for sandy with rock boulders ground. The vibration seemed to come from random directions. For this reason, it is assumed that waves in this ground type propagate through a number of reflections before arriving at the instrument geophones. The maximum value from velocity vectors was used in further analyses in sandy with rock boulders ground.

\section{Attenuation Characteristic in Each Ground Type}

\section{a) Clayey ground}

Fitting analyses were carried out for determining the attenuation of PPV over distance in clayey ground. Since only $1.0 \mathrm{~kg}$ of explosives was used in this ground type, the Eq. (2) was used instead of Eq. (1). The data and fitting results are shown in Fig. 4 and Table 2. From the first model in Table 2, the optimum result occurred when the parameter $\alpha$ (which subject to a condition of non-negative value) was zero. Therefore, it was concluded that the influence of material damping is negligible.

Table 2. Results from fitting analyses for clayey ground.

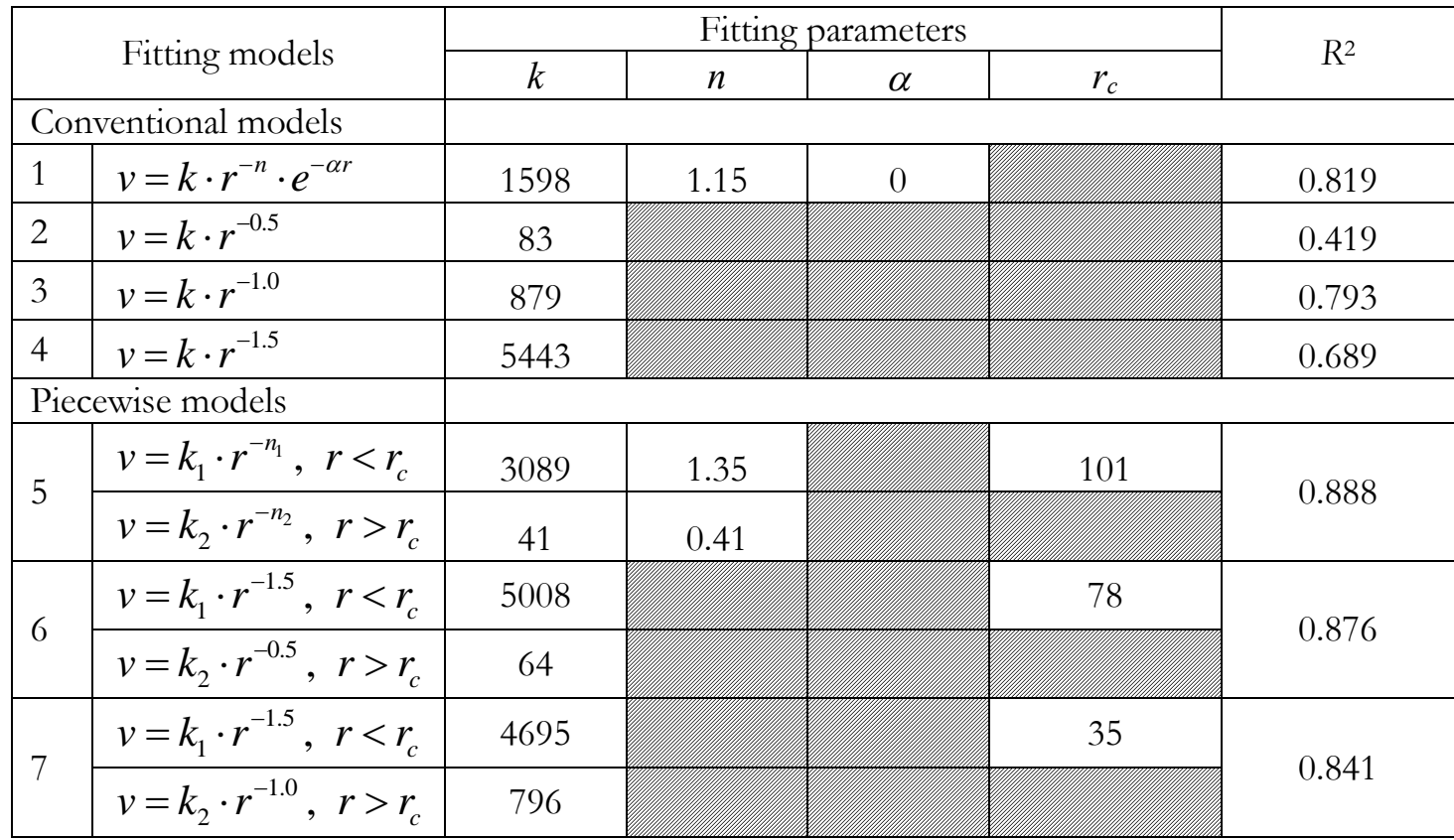

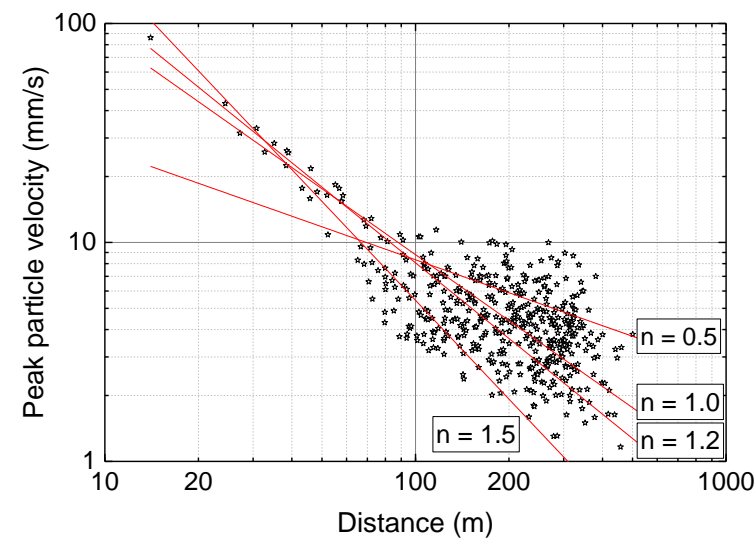

Fig. 4. Attenuation of vibration in clayey ground.

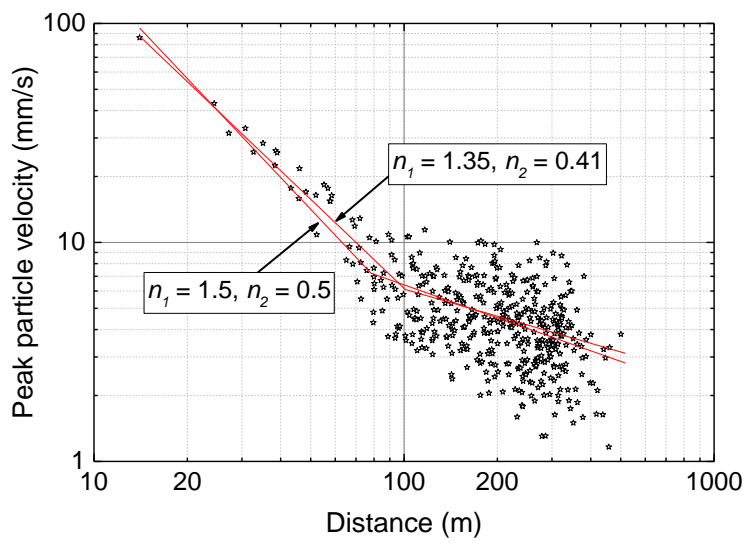

Fig. 5. Piecewise fit of vibration in clayey ground. 
Further studies were carried out by comparing the first model with the $2^{\text {nd }}$ to $4^{\text {th }}$ models which derive the value $n$ from theoretical basis. When the geometric attenuation parameter $(n)$ was fixed to 1.0 and 1.5 , the coefficients of determination $\left(R^{2}\right)$ decreased from the optimum values but still was higher than 0.65.

It was noticed from Fig. 5 that the data was well aligned with the $n=1.5$ line when the distance is less than $50 \mathrm{~m}$. Although the data became more scattered when the distance was larger than $50 \mathrm{~m}$, they tended to decrease over distance in the same rate as the $n=0.5$ line. Therefore it was assumed, based on this observation, that the vibration in the near zone was dominated by body waves whereas the vibration in the far zone was dominated by surface waves (cf. PQ/I/R and PQ/HS/O lines in Fig. 1). To validate this assumption, the data was fitted by a piecewise function shown in Eq. (6) which is the $5^{\text {th }}$ model in Table 2. Further studies were also made by setting the $n_{1}$ and $n_{2}$ to some characteristic values which are the $6^{\text {th }}$ and $7^{\text {th }}$ models in Table 2.

$$
v=\left\{\begin{array}{ll}
k_{1} r^{-n_{1}} & , \text { if } r<r_{c} \\
k_{2} r^{-n_{2}} & , \text { if } r>r_{c}
\end{array} \quad \text { subject to } k_{1} r_{c}^{-n_{1}}=k_{2} r_{c}^{-n_{2}}\right.
$$

Although the $5^{\text {th }}$ model gave the best $R^{2}$, the $6^{\text {th }}$ model is recommended for the interest of generalization and theoretical study.

\section{b) Sandy ground}

The procedure used in the previous section was also applied in this section. It was found that the effect of material damping was also negligible in sandy ground. For the interest of brevity, only analyses by Eq. (3) will be presented. The data and fitting results are shown in Fig. 6 and Table 3. It can be seen from the first model in Table 3 that the empirical values of $n$ ranged in between 1.20 to 1.40 with a minimum $R^{2}$ of 0.637 . When the geometric attenuation parameter $(n)$ was fixed to 1.0 and 1.5 , the coefficient of determination $\left(R^{2}\right)$ slightly decreased from the optimum values.

To investigate whether the attenuation rate in the near zone is different from the one in the far zone or not, the piecewise fitting analyses were carried out by assuming the value of $n_{1}$ to be 1.5 for the interest of unification with the case of clayey ground. The fit results of the $4^{\text {th }}$ model in Table 3 showed that the optimum values of $n_{2}$ were close to 0.5 for the explosive weight of 3 and $4 \mathrm{~kg}$ but not for the case of $2 \mathrm{~kg}$ explosive. Since the data was not available after the distance of $500 \mathrm{~m}$ in the latter case, the behavior of $n=$ 0.5 type might not be recognized by the fitting algorithm.

Table 3. Results from fitting analyses for sandy ground.

\begin{tabular}{|c|c|c|c|c|c|c|c|c|}
\hline & \multirow{2}{*}{ Fitting models } & \multirow{2}{*}{$\begin{array}{l}\text { Explosive } \\
\text { weight } \\
\text { (kg) }\end{array}$} & \multicolumn{5}{|c|}{ Fitting parameters } & \multirow{2}{*}{$R^{2}$} \\
\hline & & & $k_{1}$ & $n_{1}$ & $k_{2}$ & $n_{2}$ & $r_{c}$ & \\
\hline \multicolumn{9}{|c|}{ Conventional models } \\
\hline \multirow{3}{*}{1} & \multirow{3}{*}{$v=k \cdot r^{-n}$} & 2 & 3257 & 1.29 & & & & 0.827 \\
\hline & & 3 & 3268 & 1.20 & & & & 0.830 \\
\hline & & 4 & 5172 & 1.40 & & & & 0.637 \\
\hline \multirow{3}{*}{2} & \multirow{3}{*}{$v=k \cdot r^{-1.0}$} & 2 & 1276 & & & & & 0.783 \\
\hline & & 3 & 1500 & & & & & 0.813 \\
\hline & & 4 & 1137 & & & & & 0.599 \\
\hline \multirow{3}{*}{3} & \multirow{3}{*}{$v=k \cdot r^{-1.5}$} & 2 & 6100 & & & & & $\begin{array}{l}0.811 \\
\end{array}$ \\
\hline & & 3 & 9734 & & & & & 0.808 \\
\hline & & 4 & 7552 & & & & & 0.635 \\
\hline \multicolumn{9}{|c|}{ Piecewise models } \\
\hline \multirow{3}{*}{4} & \multirow{3}{*}{$\begin{array}{l}v=k_{1} \cdot r^{-1.5}, r<r_{c} \\
v=k_{2} \cdot r^{-n_{2}}, r>r_{c}\end{array}$} & 2 & 6100 & & 2884 & 1.39 & 1244 & 0.811 \\
\hline & & 3 & 9458 & & 253 & 0.69 & 85 & 0.852 \\
\hline & & 4 & 7486 & & 246 & 0.79 & 121 & 0.640 \\
\hline \multirow{3}{*}{5} & \multirow{3}{*}{$\begin{array}{l}v=k_{1} \cdot r^{-1.5}, r<r_{c} \\
v=k_{2} \cdot r^{-0.5}, r>r_{c}\end{array}$} & 2 & 6100 & & 8 & & 748 & 0.811 \\
\hline & & 3 & 9485 & & 91 & & 104 & 0.851 \\
\hline & & 4 & 7501 & & 47 & & 159 & 0.639 \\
\hline
\end{tabular}




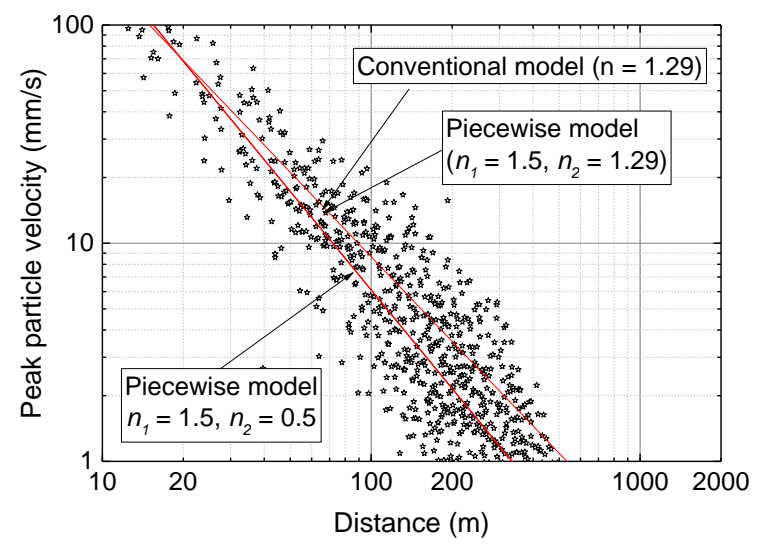

a) $2 \mathrm{~kg}$ explosive

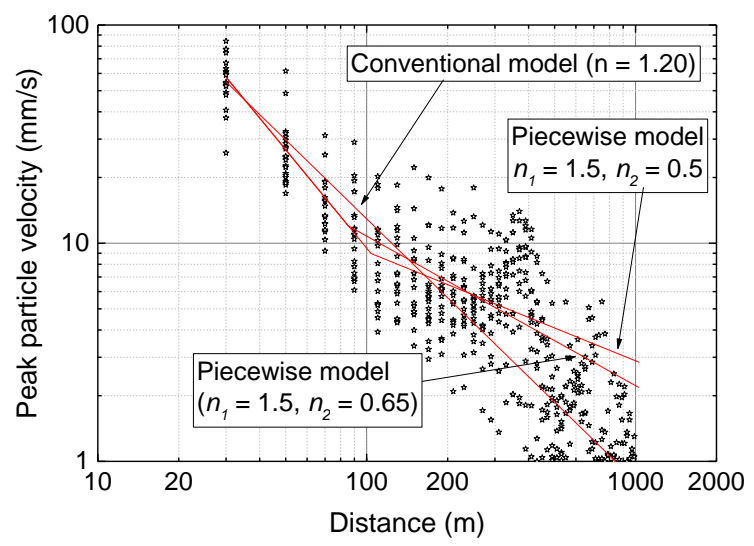

b) $3 \mathrm{~kg}$ explosive

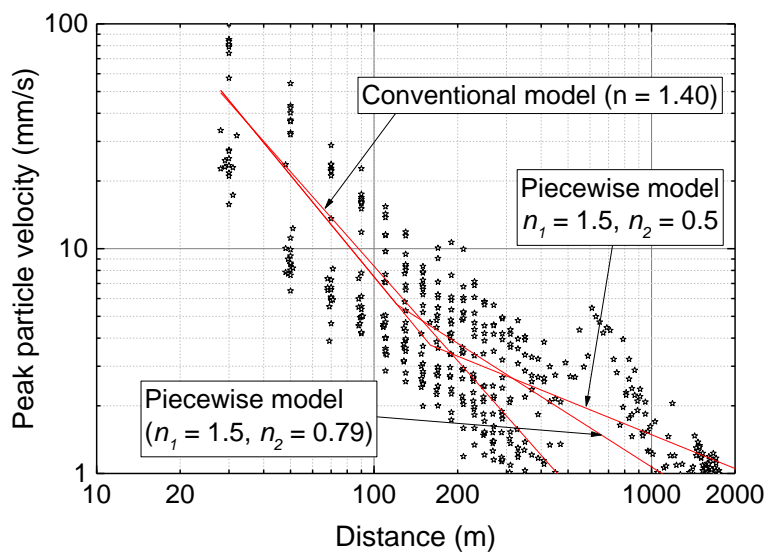

c) $4 \mathrm{~kg}$ explosive

Fig. 6. Attenuation of vibration in sandy ground.

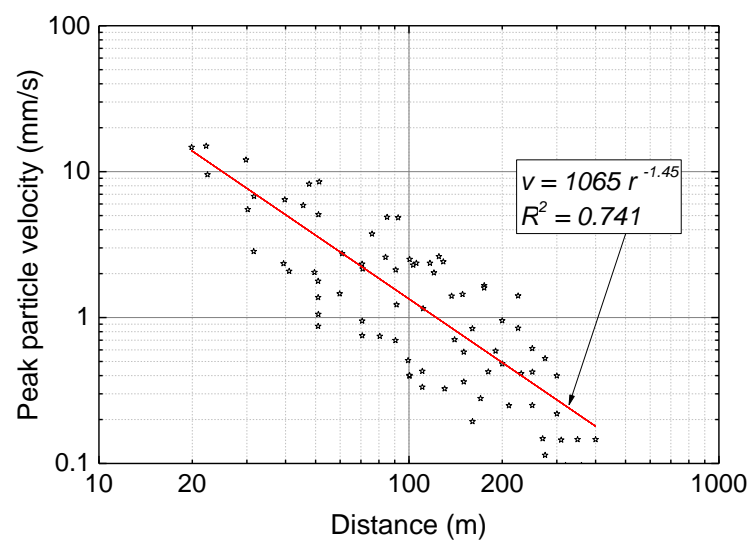

a) Original scale

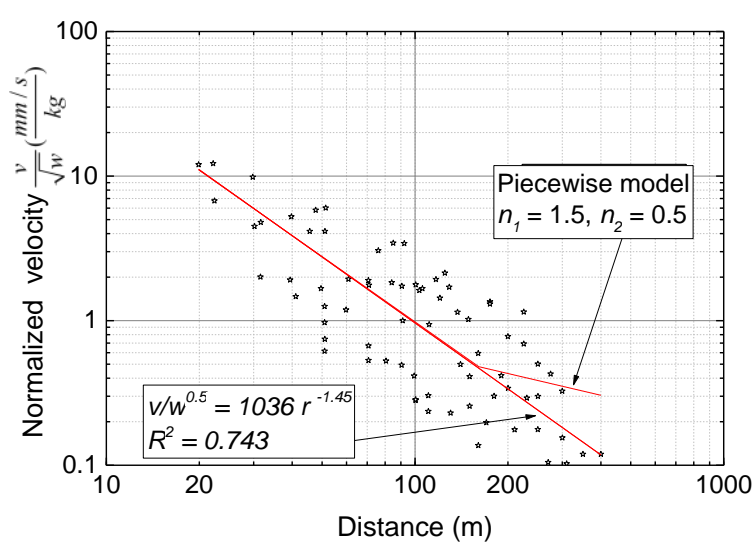

b) Normalized by explosive weight

Fig. 7. Attenuation of vibration in sandy with rock boulders ground.

Finally, when the $n_{1}$ and $n_{2}$ were fixed to 1.5 and 0.5 respectively, the coefficients of determination $\left(R^{2}\right)$ decreased slightly from the $4^{\text {th }}$ model but still better than the $1^{\text {st }}$ model except for the case of the $2 \mathrm{~kg}$ explosive. Again, the fit algorithms decided to use the $n_{1}$ which was close to the optimum value (1.29) than the $n_{2}$. 
c) Sandy with rock boulders ground

Only $1.5 \mathrm{~kg}$ of explosives was used in this ground type. Due to the reason mentioned earlier, the maximum values from velocity vectors were used instead of the data from vertical geophones. The fit result is shown in Fig. 7. When the data was normalized by the square root of the explosive weight, which will be explained in the next section, the slope of the best fit line became close to 1.5 with slightly improved $R^{2}$. It can be concluded that the attenuation of the $n=1.5$ type can be adopted for this ground type. It was also observed that the vibration level in sandy with rock boulders ground was significantly smaller than the other ground types.

\section{The Influence of Explosive Weight and Ground Type}

Based on Eq. (2), the magnitude of vibration near to its source (i.e. $r=1 \mathrm{~m}$ ) is controlled by two parameters which are explosive weight and the parameter $k$.

The influence of explosive weight on vibration level was studied from the measurements in sandy ground where the explosive weight varied between $2-4 \mathrm{~kg}$. Based on the first model in Table 3, the values of $k$ seemed to be proportional with the explosive weight. However, when the parameter $n$ was fixed to either of 1.0 or 1.5 , the values of $k$ did not properly vary with the explosive weight. For this reason, an alternative strategy based on the fundamentals of wave propagation theory was adopted.

From a theoretical point of view, the energy of vibration is proportional to the square of the amplitude of a wave. Since the energy of explosive is proportional to its weight, the amplitude of a wave could be normalized by the square root of explosive weight. The normalized equations as well as their qualities of fit for all ground types are shown in Table 4 . The $R^{2}$ of all cases were higher than 0.7 and seemed to be sufficient for practical purposes.

The parameter $k$ reflects the influences from remaining unconsidered factors, such as the energy loss at the detonation point, the stiffness of the ground, and so on. This parameter was empirically linked with ground type in this study. From Table 4 , the $k_{1}$ of sandy ground and sandy with rock boulders ground compared to clayey ground were $87 \%$ and $20 \%$, respectively. The corresponding ratios for the $k_{2}$ were $48 \%$ and $9 \%$ for sandy ground and sandy with rock boulders ground, respectively.

It was also noticed that the value of $r_{c}$, or the boundary where the attenuation characteristic changed from $n=1.5$ to $n=0.5$, varied in opposite direction with $k_{1}$ and $k_{2}$. The $r_{c}$ increased to 1.79 and 2.06 times when the ground type changed from clayey to sandy and sandy with rock boulders, respectively.

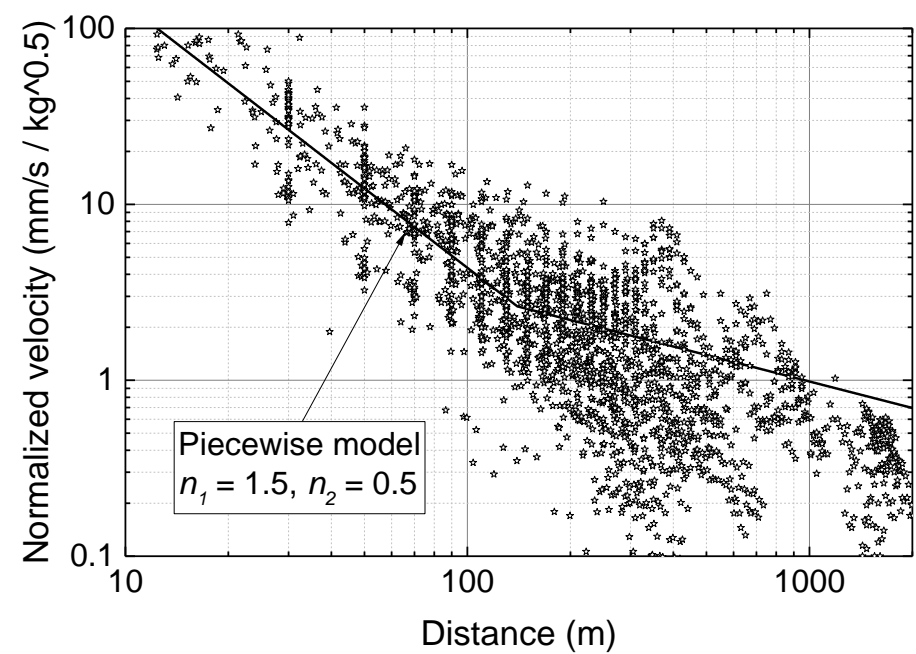

Fig. 8. Prediction model (Normalized velocity for sandy ground). 
Table 4. Results from fitting analyses with a consideration on explosive weight.

\begin{tabular}{|c|c|c|c|c|c|}
\hline \multirow{2}{*}{ Fitting models } & \multirow{2}{*}{ Ground type } & \multicolumn{3}{|c|}{ Fitting parameters } & \multirow{2}{*}{$\mathrm{R}^{2}$} \\
\cline { 2 - 5 } & $k_{1}$ & $k_{2}$ & $r_{c}$ & \multirow{2}{*}{} \\
\hline $\begin{array}{l}\bar{v}=k_{1} \cdot r^{-1.5}, r<r_{c} \\
\bar{v}=k_{2} \cdot r^{-0.5}, r>r_{c}\end{array}$ & Clayey & 5008 & 64 & 78 & 0.876 \\
\cline { 2 - 6 } & Sandy & 4356 & 31 & 140 & 0.793 \\
\hline where $\bar{v}=v / \sqrt{w}$ & Sandy with rock boulders & 981 & 6 & 161 & 0.743 \\
\hline
\end{tabular}

\section{Frequency Content and Comparison with DIN 4150's Guideline}

DIN-4150 suggests that the effects of a vibration event on structures can be evaluated from its maximum velocity accompanied with the main vibration frequency (usually referred to as the dominant frequency). The guideline in DIN-4150 can be explained by three lines in Fig. 9. For instance, significant damage will not occur on buildings under preservation order when a point, representing dominant frequency-maximum velocity pair, is lower than the L3 line.

To adopt the aforementioned guideline, it was interesting to know the variation of dominant frequency over distance such as the ones shown in Fig. 10. Based on the same figure, the dominant frequency was not correlated with the distance, but rather depends on the ground condition. Statistics in Table 5 showed that the dominant frequency of saturated sandy ground were higher than the ones of dry ground. For sandy with rock boulders ground, the dominant frequency was high and scattered over a wider range. The dominant frequency of clayey ground was also higher and less scattered than other cases.

It can be seen from Fig. 9 that less vibration velocity is permitted when the dominant frequency decreases. Therefore the dominant frequency at $\mu-2 \sigma$, which is approximately lower than $98 \%$ of the population, will be assumed in further analyses for the conservative sake. Since the limit values of L1, L2, L3 lines stop decreasing when the dominant frequency is lower than $10 \mathrm{~Hz}$, the frequency of $10 \mathrm{~Hz}$ will be assumed when a $\mu-2 \sigma$ is less than $10 \mathrm{~Hz}$.

Using the proposed formula in Table 4, the dominant frequencies in Table 5 and DIN 4150's guideline, the setback distances between residential buildings and a 2-kg explosive at $80 \%$ one-side upper prediction level were found to be 53,149 and $221 \mathrm{~m}$ for rocky, sandy and clayey grounds, respectively.

Table 5. Statistics of dominant frequency in each ground type.

\begin{tabular}{|l|c|c|c|c|}
\hline Ground type & Sample size & $\begin{array}{c}\text { Mean, } \mu \\
(\mathrm{Hz})\end{array}$ & $\begin{array}{c}\text { S.D., } \sigma \\
(\mathrm{Hz})\end{array}$ & $\begin{array}{c}\mu-2 \sigma \\
(\mathrm{Hz})\end{array}$ \\
\hline Clayey ground (Saturate) & 871 & 49 & 14 & 21 \\
\hline Sandy ground (Dry) & 1116 & 17 & 18 & $<10$ \\
\hline Sandy ground (Saturate) & 978 & 42 & 21 & $<10$ \\
\hline Sandy ground (all data) & 2094 & 29 & 23 & $<10$ \\
\hline Sandy with rock boulders ground (Radial direction) & 111 & 45 & 52 & $<10$ \\
\hline Sandy with rock boulders ground (Transverse direction) & 111 & 36 & 38 & $<10$ \\
\hline Sandy with rock boulders ground (Vertical direction) & 524 & 31 & 44 & $<10$ \\
\hline
\end{tabular}




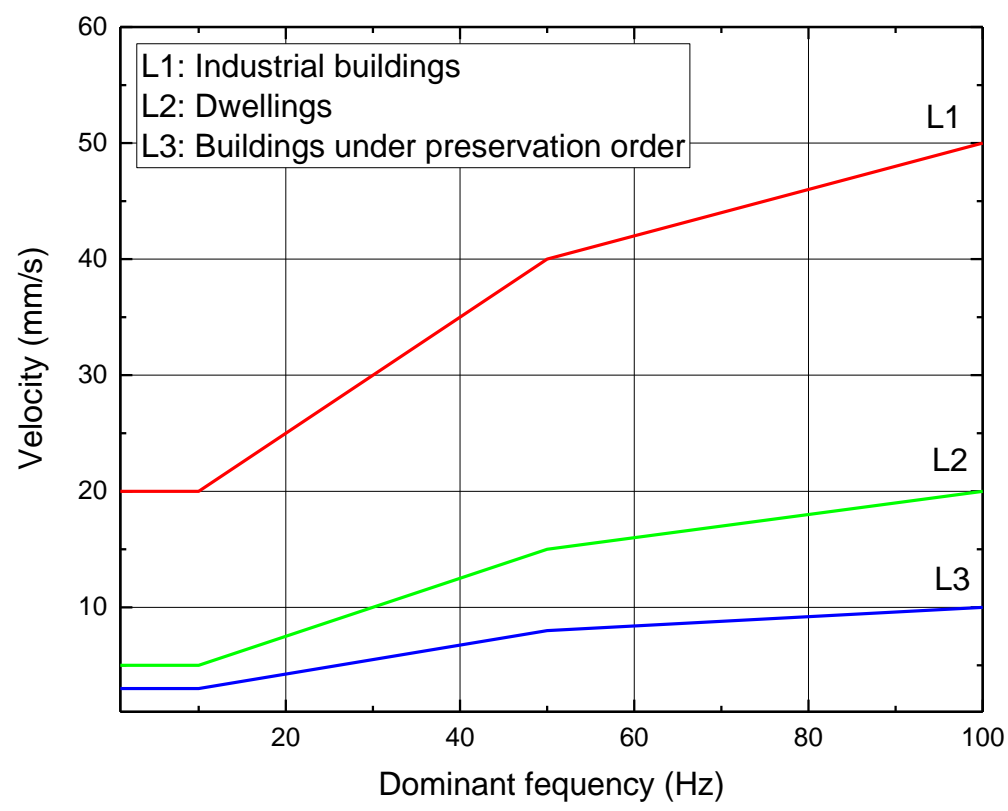

Fig. 9. Guideline values at building foundations for short-term vibration (after DIN 4150).

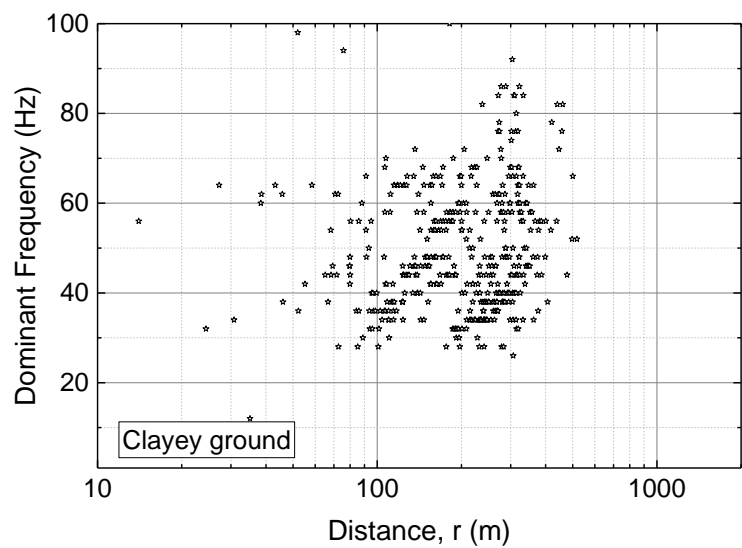

a) Clayey ground (Saturate)

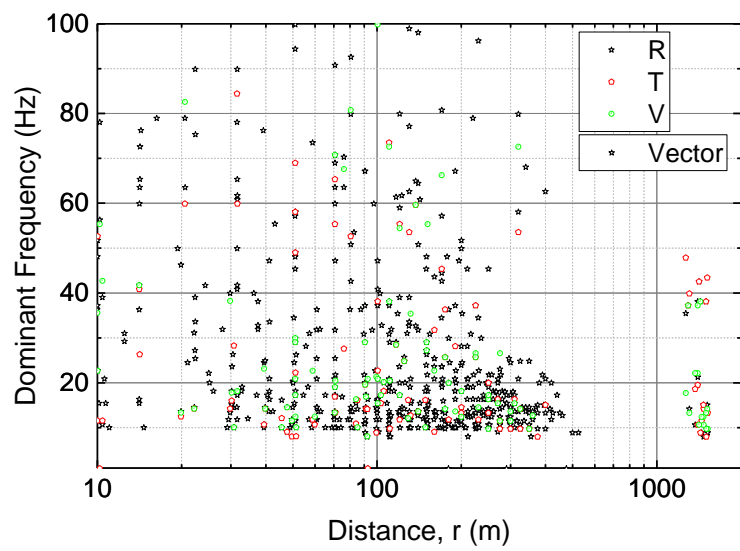

c) Sandy with rock boulders ground

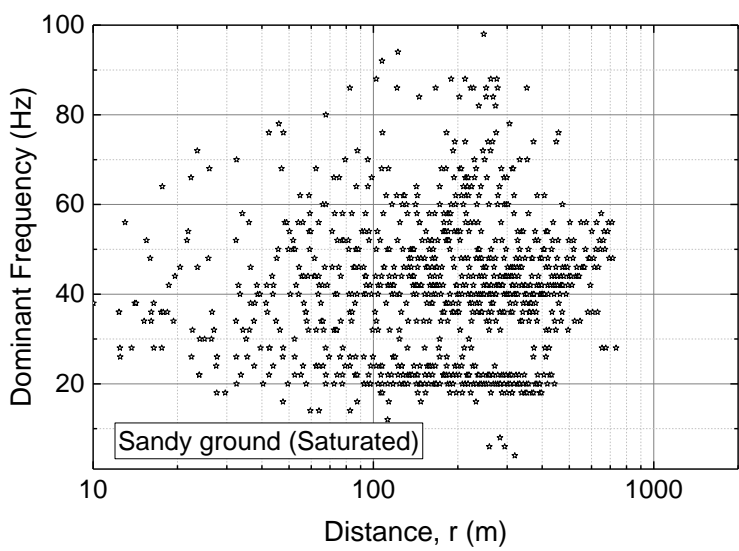

b) Sandy ground (Saturate)

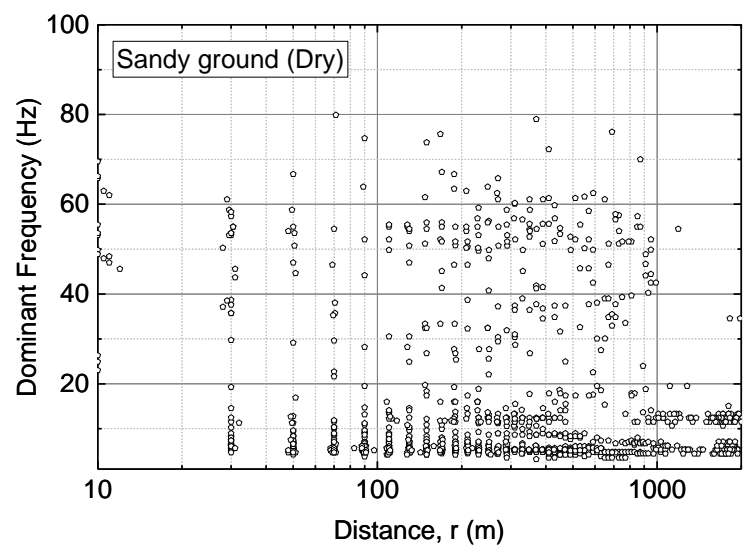

d) Sandy ground (Dry)

Fig. 10. Variation of dominant frequency with distance in each ground type. 


\section{Conclusion}

Ground vibrations were measured from ten on-land seismic reflection surveys in Thailand. Explosives in this study were buried and packed in boreholes at depths of $9 \sim 23 \mathrm{~m}$, having weights of $1 \sim 4 \mathrm{~kg}$ and length-to-diameter ratios of $6 \sim 25$. The studied areas were grouped into three geology conditions, namely sandy ground, clayey ground and sandy with rock boulders grounds. Based on the results in this study, the conclusions can be made as follows;

1) Vibrations in clayey and sandy grounds were dominated by the vertical component. Therefore, the vibration assessment may be cost-effectively done by merely vertical geophones, or, by vertical geophones and cross-checked by a few of triaxial geophones. On the contrary, the peak particle velocity occurred in random directions in sandy with rock boulders ground. Therefore, it is recommended to assess the vibration damage by the velocity vector instead of one-directional velocity for this ground type.

2) The attenuation of vibration can be described by setting the geometric damping parameter to 1.5 for the near zone and to 0.5 for the far zone. This characteristic conformed to the condition of body waves generated by an impulsive point source and Rayleigh waves generated by harmonic point source, respectively. The latter could have occurred if the ground vibrated under its natural mode of vibration.

3) Vibration velocity at a distance can be determined from equations shown in the table that follows. The units for $v, r, r c$, and $w$ are $\mathrm{mm} / \mathrm{s}, \mathrm{m}, \mathrm{m}, \mathrm{kg}$, respectively. It is noted that equations on the left most column will only give the best estimate of the mean value. Therefore, it is recommended to add the predicted normalized velocity $(\bar{v})$ by a constant of 1 . By doing this, the modified value will be approximately at $80 \%$ one-side upper prediction level provided that $r>r_{c}$.

\begin{tabular}{|c|c|c|c|c|c|}
\hline \multirow{2}{*}{ Fitting models } & \multirow{2}{*}{ Ground type } & \multicolumn{3}{|c|}{ Fitting parameters } & \multirow{2}{*}{$R^{2}$} \\
\hline & & $k_{1}$ & $k_{2}$ & $r_{c}$ & \\
\hline \multirow{3}{*}{$\begin{array}{l}\bar{v}=k_{1} \cdot r^{-1.5}, r<r_{c} \\
\bar{v}=k_{2} \cdot r^{-0.5}, r>r_{c} \\
\text { where } \bar{v}=v / \sqrt{w}\end{array}$} & Clayey & 5008 & 64 & 78 & 0.876 \\
\hline & Sandy & 4356 & 31 & 140 & 0.793 \\
\hline & Sandy with rock boulders ground & 981 & 6 & 161 & 0.743 \\
\hline
\end{tabular}

4) Observed data shows no significant correlation between the dominant frequency and distance. Although the observed data were rather scattered, the dominant frequency seemed to be related with ground condition. The dominant frequencies of vibration were around $17 \mathrm{~Hz}$ in dry sandy ground, $42 \mathrm{~Hz}$ in saturated sandy ground, $49 \mathrm{~Hz}$ in saturated clayey ground and $31 \sim 45 \mathrm{~Hz}$ in sandy with rock boulders ground. The presence of ground water could increase the dominant frequency significantly.

5) Due to the uncertainty in determining the dominant frequencies of vibration in each ground type, the dominant frequencies were assumed to be the values at the $2.5^{\text {th }}$ percentile for the conservative sake in the vibration assessment in this study. Based the proposed formula and the assumed frequencies, the setback distances (approximately at $80 \%$ prediction level) between residential buildings and a 2 -kg explosive were found to be 53,149 and $221 \mathrm{~m}$ for sandy with rock boulders, sandy and clayey grounds, respectively.

\section{References}

[1] S. Tangchawal, "Assessment on rock blasting impacts," presented at Symposium on Mineral, Energy and Water Resources of Thailand: Towards the Case Histories in Thailand, Bangkok, Thailand, 2000.

[2] S. Tangchawal, "Planning and evaluation for quarries: Case histories in Thailand," presented at LAEG2006, Nottingham, United Kingdom, 2006.

[3] J. W. Kopp and D. E. Siskind, "Effects of millisecond-delay intervals on vibration and airblast from surface coal mine blasting," Report of Investigations 9026, US Department of the Interior, Bureau of Mines, 1986.

[4] C. H. Dowding and C. Dowding, Construction Vibrations. NJ: Prentice Hall, 1996, pp. 264-268.

[5] P. K. Singh and M. P. Roy, "Damage to surface structures due to blast vibration," International Journal of Rock Mechanics and Mining Sciences, pp. 949-961, 2010.

[6] P. Segarra, L. M. López, and J. A. Sanchidrián, "Uncertainty in measurements of vibrations from blasting," Rock. Mechanics and Rock. Engineering, pp.1-8, 2012. 
[7] B. M. New, "Ground vibration caused by construction works," Tunnelling and Underground Space Technology, vol. 5, no. 3, pp. 179-190, 1990.

[8] G. R. Tripathy and I. D. Gupta, "Prediction of ground vibrations due to construction blasts in different types of rock," Rock Mechanics and Rock Engineering, vol. 35, no. 3, pp. 195-204, 2002.

[9] Ö. Uysal, E. Arpaz, and M. Berber, "Studies on the effect of burden width on blast-induced vibration in open-pit mines," Environmental Geology, vol. 53, no. 3, pp. 643-650, 2007.

[10] B. Müller, J. Hausmann, and H. Niedzwiedz, "Comparison of different methods of measuring and calculating blast vibrations in rock masses," presented at The 4th EFEE World Conference, Vienna, 2007.

[11] C. Kuzu,. "The importance of site-specific characters in prediction models for blast-induced ground vibrations," Soil Dynamics and Earthquake Engineering, vol. 28, no. 5, pp. 405-414, 2008.

[12] D. H. Johnston, M. N. Toksoz, and A. Timur. "Attenuation of seismic waves in dry and saturated rocks: II. Mechanisms,” Geophysics, vol. 44, no. 4, pp. 691-711 1979.

[13] H. Ghasemzadeh and A. A. Abounouri. "Compressional and shear wave intrinsic attenuation and velocity in partially saturated soils," Soil Dynamics and Earthquake Engineering, vol. 51, pp. 1-8, 2013.

[14] D.-S. Kim and J.-S. Lee, "Propagation and attenuation characteristics of various ground vibrations," Soil Dynamics and Earthquake Engineering, vol. 19, no. 2, pp. 115-126, 2000.

[15] H. Amick and M. Gendreau, "Construction vibrations and their impact on vibration-sensitive facilities," in ASCE Construction Congress, 2000, vol. 6, pp. 758-767.

[16] A. Ghosh and J. J. Daemen, "A simple new blast vibration predictor (based on wave propagation laws)," in The 24th US Symposium on Rock Mechanics (USRMS), 1983.

[17] N. Ambraseys and A. Hendron, "Dynamic behaviour of rock masses," Rock Mechanics in Engineering Practices. K. G. Stagg and O.C. Zienkiewicz, Eds. London: Wiley \& Sons, 1968, pp. 203-236.

[18] C. H. Dowding and L. M. McKenna, "Crack response to long-term environmental and blast vibration effects," Journal of Geotechnical and Geoenvironmental Engineering, vol. 131, no. 9, pp. 1151-1161, 2005.

[19] J. F., Devine, "Vibration levels from multiple holes per delay quarry blasts," Seismological Research Letters, vol. 33, no. 3, pp. 32-39, 1962.

[20] D. E. Siskind, M. S. Stagg, J. W. Kopp, and C. Dowding, "Structure response and damage produced by ground vibration from surface mine blasting," Report of Investigations 8507, Twin Cities, MN, USA; Twin Cities Research Center, Northwestern Univ., Evanston, IL, USA, 1980.

[21] U. Langefors and B. Kihlström, The Modern Technique of Rock Blasting. New York: John Wiley \& Sons, 1978.

[22] R. Gustafsson, Swedish Blasting Technique. Sweden: SPI Gothenburg.

[23] Indian Standard, Criteria for Safety and Design of Structures Subjected to Underground Blast, ISI, IS-6922, 1973. 